\title{
Clinical Management of Ovarian Small-Cell Carcinoma of the Hypercalcemic Type \\ A Proposal for Conservative Surgery in an Advanced Stage of Disease
}

\author{
Ramon H.M. Dykgraaf, MD, * Diederick de Jong, MD, PhD, $†$ Mirjam van Veen, MSc, * \\ Patricia C. Ewing-Graham, FRCPath, $\neq$ Theo J.M. Helmerhorst, MD, PhD, $\S$ \\ and Maria E.L. van der Burg, MD, PhD//
}

\begin{abstract}
Ovarian small-cell carcinoma of the hypercalcemic type is a rare and highly malignant tumor. In two thirds of the patients, the tumor is associated with asymptomatic paraneoplastic hypercalcemia. The diagnosis may be impeded; the tumor must be distinguished from other tumors with similar features.

This tumor occurs predominantly in young women and is merely lethal. The 1-year survival is solely $50 \%$, with an overall 5 -year survival rate of approximately $10 \%$. It is believed that the empirical treatment characterized by combination of radical surgery, chemotherapy, and radiotherapy results in the most favorable outcome in terms of survival. However, the outcome remains extremely poor despite this aggressive approach.

Alternatively, these poor survival rates may justify a less aggressive fertility sparing approach without compromising the outcome. Such an approach is illustrated by a case report involving a patient with ovarian small-cell carcinoma of the hypercalcemic type, FIGO stage IIIC. A fertility-sparing approach was used, consisting of conservative surgery followed by induction chemotherapy, interval debulking surgery, and local radiotherapy. During follow-up of 60 months, there was no evidence of disease and the normal menstrual cycle resumed.

In addition to this case report, histopathological features, different therapeutic modalities, and outcome of ovarian small-cell carcinoma of the hypercalcemic type is reviewed. This report suggests that a fertility-sparing approach may be just as feasible as the generally applied aggressive approach.
\end{abstract}

Key Words: Ovarian cancer, Small-cell carcinoma of the hypercalcemic type, Conservative surgery, Neoadjuvant chemotherapy, Survival

(Int J Gynecol Cancer 2009;19: 348-353)

*Department of Obstetrics and Gynecology, Erasmus MC, University Medical Center, Rotterdam, the Netherlands; $\uparrow$ Division of Gynecologic Oncology, Department of Obstetrics and Gynecology, Princess Margaret Hospital University Health Network, Toronto, Canada; $\ddagger$ Josephine Nefkens Institute, Department of Pathology, Erasmus MC; §Division of Gynecologic Oncology, Department of Obstetrics and Gynecology, Erasmus MC/Daniel de Hoed; ||Department of Medical Oncology, Erasmus MC, University Medical Center, Rotterdam, the Netherlands.

Address correspondence and reprint requests to Diederick de Jong, MD, PhD,

Division of Gynecologic Oncology, Department of Obstetrics and

Gynecology, Princess Margaret Hospital University Health Network,

610 University Ave, Suite M700, Toronto, Ontario, M5G 2M9 Canada.

E-mail: Diederick.DeJong@uhn.on.ca.

Copyright $(\mathcal{C} 2009$ by IGCS and ESGO

ISSN: 1048-891X

DOI: 10.1111/IGC.0b013e3181a1a116
The rare ovarian small-cell carcinoma of the hypercalcemic type is predominantly observed in young women. Fewer than 250 cases have been reported in the literature. ${ }^{1,2}$ Ovarian tumors in young women are often germ-cell or sex-cord tumors, whereas ovarian small-cell carcinomas of the hypercalcemic type represent a minority. The average age of occurrence of these tumors is 23.9 years (range, $1-55$ years). ${ }^{3-5}$

Ovarian small-cell carcinoma of the hypercalcemic type is generally in FIGO stage III at first presentation. ${ }^{6}$ In most cases, a unilateral tumor is present. The average diameter of the tumor is $15 \mathrm{~cm}$ (range, $6-26 \mathrm{~cm}$ ). ${ }^{3}$ The 1-year survival is solely $50 \%$, with an overall 5-year survival rate of approximately $10 \%{ }^{3,7}$

The scarcity, the histological features, the unsolved origin of these tumor cells, and wide range of potential differential diagnoses impede pathological characterization. ${ }^{3,8}$ An accurate diagnosis is mandatory in relation to the therapeutic consequences. ${ }^{9,10}$ 
It is widely believed that a combination of treatment modalities, consisting of radical surgery, chemotherapy, and radiotherapy, results in the most favorable outcome in terms of survival. However, this aggressive approach is empirically established based on single case histories and small series. ${ }^{2,11}$ It is under debate whether the poor survival rates of ovarian small-cell carcinoma of the hypercalcemic type justify aggressive treatment modalities without obtaining a reasonable outcome. Alternatively, the dramatically poor survival rates and subsequently, the limited time to have children, may compromise the need for less aggressive fertility sparing approaches.

A review of the available literature regarding the pathological characterization, various treatment modalities, and outcome is summarized. As a consequence of the poor outcome, especially in the advanced stages of disease, a fertility sparing approach may be just as justified as an aggressive radical approach. The feasibility of such a fertility sparing approach is illustrated by a case report.

\section{CASE REPORT}

A 23-year-old woman presented an acute abdomen. A rightsided ovarian tumor with a diameter of $13 \mathrm{~cm}$ was found. There was no significant past medical history and the menstrual cycle was normal. Laboratory tests demonstrated an elevated C-reactive protein of $120 \mathrm{kU} / \mathrm{L}$ and white blood counts of $6.7 \times 10^{9} / \mathrm{L}$. Other tests were normal. Torsion of the right ovary was suspected, and a laparotomy was performed. A torsion of an enlarged right ovary was diagnosed with a normal aspect of the left ovary, uterus, and other intra-abdominal organs. Retroperitoneal lymph nodes were regarded as reactively enlarged. The right adnex was surgically resected. Preliminary pathological assessment of the right ovary yielded the diagnosis of ovarian dysgerminoma.

The patient was referred to a tertiary referral center for further treatment. Vaginal ultrasound and x-ray showed no abnormalities. Computed tomography scan of the abdomen and pelvis demonstrated enlarged retroperitoneal lymph nodes (renal and paraaortal). Laboratory tests showed elevated ASAT, LDH, and Ca-125 serum levels (41 U/L, $488 \mathrm{U} / \mathrm{L}$, and $45 \mathrm{kU} / \mathrm{L}$, respectively). All other tests, including serum calcium levels, human chorionic gonadotropin (hCG), and $\alpha$-fetoprotein (AFP) were normal. Oral

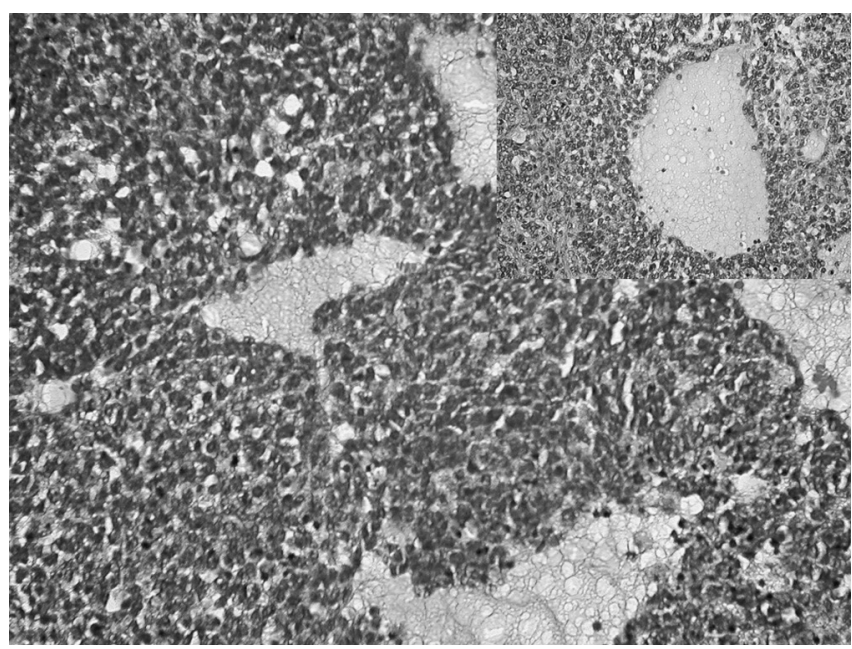

FIGURE 1. Hematoxylin and eosin slides of small-cell carcinoma of the hypercalcemic type of the right ovary in a 23-year woman. A population of small, hyperchromatic tumor cells surrounds follicle-like spaces $(\times 200)$. Insert: a small-cell pattern is visible with a hypocellular region surrounded by polygonal cells $(\times 400)$.
TABLE 1. Immunohistochemical profile of the presented patient with ovarian small-cell carcinoma to the hypercalcemic type

\begin{tabular}{|c|c|c|c|}
\hline \multicolumn{4}{|c|}{$\begin{array}{c}\text { Immunohistochemistry in Ovarian Small-Cell Tumor of the } \\
\text { Hypercalcemic Type }\end{array}$} \\
\hline & $\begin{array}{c}\text { Extensive/ } \\
\text { Moderate } \\
\text { Positive }\end{array}$ & $\begin{array}{c}\text { Focal/ } \\
\text { Occasional } \\
\text { Positive }\end{array}$ & Negative \\
\hline \multicolumn{4}{|c|}{ Immunohistochemical markers: } \\
\hline AFP & & & $\mathrm{X}$ \\
\hline Alk1 & & & $\mathrm{X}$ \\
\hline CAM 5.2 & $X$ & & \\
\hline CD10 & $\mathrm{X}$ & & \\
\hline CD30 & & & $\mathrm{X}$ \\
\hline CD45 & & & $\mathrm{X}$ \\
\hline CD117 & & & $\mathrm{X}$ \\
\hline Chromoganin & & & $\mathrm{X}$ \\
\hline Cytokeratin & $\mathrm{X}$ & & \\
\hline Desmin & & & $\mathrm{X}$ \\
\hline EMA & & $\mathrm{X}$ & \\
\hline hCG & & & $\mathrm{X}$ \\
\hline Inhibin & & $\mathrm{X}$ & \\
\hline NSE & & $\mathrm{X}$ & \\
\hline Okt $3 / 4$ & & & $\mathrm{X}$ \\
\hline $\mathrm{p} 12$ & & & $\mathrm{X}$ \\
\hline p53 & $X$ & & \\
\hline Pankeratin & & $\mathrm{X}$ & \\
\hline PTHrP & & $\mathrm{X}$ & \\
\hline PLAP & & & $\mathrm{X}$ \\
\hline $\mathrm{S} 100$ & & & $\mathrm{X}$ \\
\hline Vimentin & $\mathrm{X}$ & & \\
\hline
\end{tabular}

contraceptives were administered in an effort to preserve ovarian function. ${ }^{12}$ Based on the initial diagnosis of dysgerminoma and the enlarged paraaortic lymph nodes, treatment was initiated with bleomycin, etoposide, and cisplatin (BEP) cycles (bleomycin $30 \mathrm{mg} / \mathrm{m}^{2}$ days $2,8,15$; etoposide $100 \mathrm{mg} / \mathrm{m}^{2}$ days $1-5$; cisplatin $20 \mathrm{mg} / \mathrm{m}^{2}$ days 1-5). Revision of the pathology yielded a diagnosis of ovarian small-cell carcinoma of hypercalcemic type. The tumor was described macroscopically as $11 \times 7 \times 5 \mathrm{~cm}$ with an incomplete capsule and areas of necrosis and bleeding. Microscopic examination of the tumor showed closely packed small round cells arranged in nests with comparatively small nuclei and scanty cytoplasm. There were striking follicle-like spaces filled with eosinophilic material in some areas. Larger tumor cells with eosinophilic cytoplasm and large paler nuclei with prominent nucleoli were also present in some areas, and there were extensive areas of necrosis (Fig. 1). The mitotic rate was high, mean of 5 per HPF in the areas with small-cell morphology.

Immunohistochemistry showed widespread positive staining for CAM 5.2, CD 10, and p53, whereas in some areas, staining with pankeratin was present. There was also focal staining for epithelial membrane antigen (EMA), and neuron-specific enolase (NSE) 
was demonstrated. Inhibin was very focally positive. WT1 showed intense cytoplasmatic positivity. Staining was negative for chromogranin, S100, desmin, placental alkaline phosphatase (PLAP), c-kit protein (CD117), CD30, hCG, AFP, CD45, OCT 3/4, and ALK1. Over-expression of $12 \mathrm{p}$ by in situ hybridization ${ }^{13}$ was absent. Based on the morphology and the immunohistochemical features (Table 1), this high-grade malignant tumor was diagnosed as an ovarian small-cell carcinoma of the hypercalcemic type.

After the final diagnosis of ovarian small-cell carcinoma of the hypercalcemic type, computed tomography scan was repeated and showed regression of the lymph nodes after the first 2 BEP cycles. It was therefore decided to continue the treatment and complete a total of 4 BEP cycles. After the fourth BEP cycle, there was a partial remission. The patient underwent a debulking and staging surgery. No macroscopic or microscopic tumor was found intra-abdominally. The uterus and left ovary were normal with no macroscopic sign of malignancy. Retroperitoneal enlarged lymph nodes were palpated and resected.

The histology of the resected lymph nodes showed tumor cells of the large cell type, arranged in nests, with eccentric nuclei and sometimes with intracytoplasmatic hyaline globules. Peritoneal biopsies were free of tumor cells. After the resection of the paraaortic lymph nodes, the paraaortal region was irradiated with 46 Gy in 23 fractions of $2 \mathrm{~Gy}$. A full remission was established for at least 68 months, and the normal menstrual cycle had resumed.

\section{OVARIAN SMALL-CELL CARCINOMA OF THE HYPERCALCEMIC TYPE}

\section{Clinical Presentation}

Patients with small-cell carcinoma of hypercalcemic type present with symptoms similar to other ovarian tumors such as lower abdominal pain and/or pelvic pain, enlargement of the abdomen, weight loss, nausea, vomiting, and anorexia. ${ }^{2,3,5}$ Two thirds of these cases are associated with hypercalcemia, ${ }^{3}$ although only $2.5 \%$ of these patients present symptoms of hypercalcemia. ${ }^{6}$ Our patient had normal serum calcium levels. In general, the increased serum calcium levels decline to physiological levels after complete surgical resection of the tumor and increase with recurrence. Serum calcium levels may serve as a marker for treatment response and recurrences. ${ }^{14}$ The pathophysiology of hypercalcemia is unclear. It has been postulated that parathyroid hormone or parathyroid hormone-related protein (PTHrp) or a tumor-induced calcium release by nontumor-related tissues may play a vital role. ${ }^{1,8}$

\section{Etiology}

This tumor was described as a distinct entity for the first time in $1982 .^{2}$ It should be distinguished from small-cell carcinoma of the pulmonary type, neuroendocrine carcinoma and from metastatic pulmonary small-cell carcinoma and can easily be confused with the highly malignant germ cell tumors of the ovary, specifically dysgerminoma and granulosa cell tumors., ${ }^{3,17}$ The origin of ovarian small-cell carcinoma of the hypercalcemic type is unclear. ${ }^{2}$ A germ cell as origin for this type of ovarian tumor has been suggested. ${ }^{6}$ However, electron microscopic examination has demonstrated the presence of epithelial features. ${ }^{18}$ A number of cases have been reported of a familial occurrence of this tumor. $^{6,12,19}$ The evidence for a germ cell origin and inheritance remains inconclusive, the tumor may be a unique tumor entity. ${ }^{1,10}$

\section{Histopathological Analysis}

The pathological assessment of ovarian small-cell carcinoma of the hypercalcemic type may be problematic by reason of similarities with other ovarian neoplasms and the unsolved origin of these tumor cells. ${ }^{3,8,16}$ Moreover, approximately $50 \%$ of these tumors exhibit a large cell component besides the typically small round cells with scant cytoplasm. ${ }^{20}$ The presence of solely large cell tumor observed in the surgically removed lymph nodes after neoadjuvant chemotherapy in our patient is noteworthy. In these tumors, numerous mitoses are commonly present, varying from field to field, ranging 16 to 50 per 10 high power fields. ${ }^{3}$ Assessment of this tumor can be also be hindered by the lack of any specific immunohistochemical profile. ${ }^{8,21}$

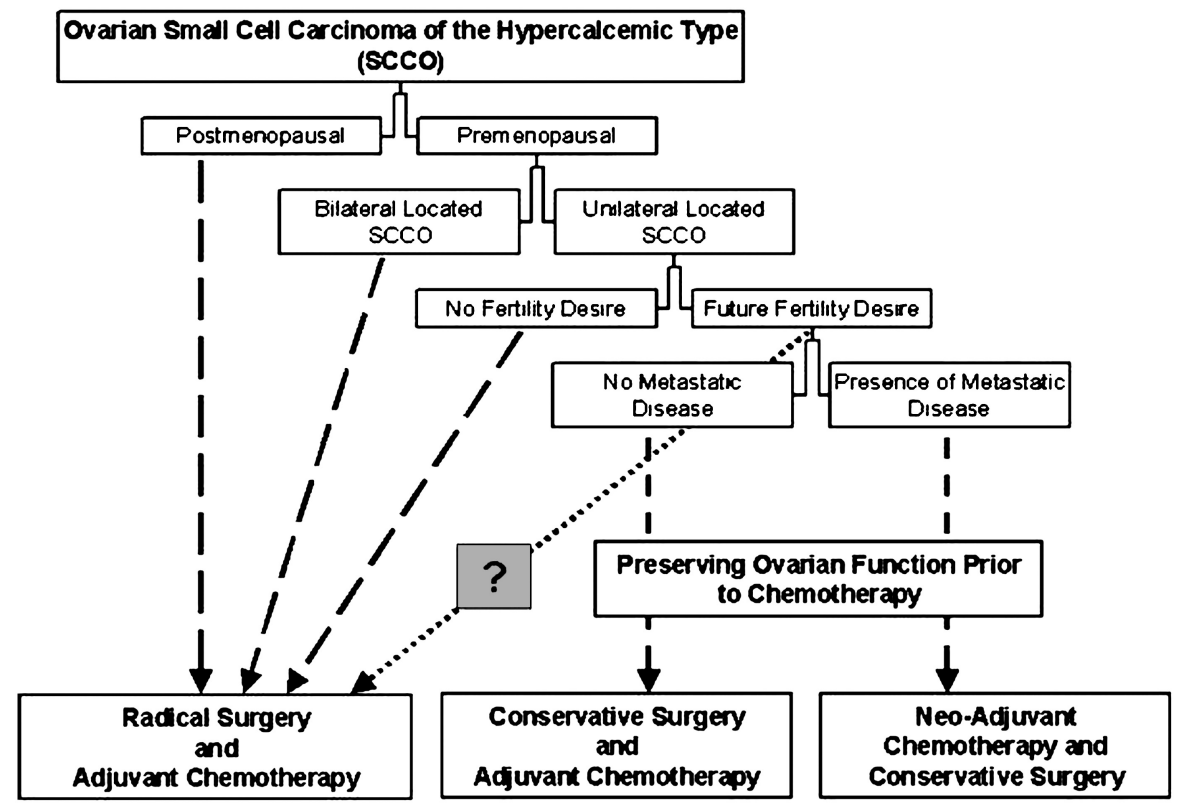

FIGURE 2. Proposed algorithm for the treatment of patients with small-cell carcinoma of the hypercalcemic type of the ovary. The proposed alternatives of conservative surgery may have an equally grim prognosis. However, the consequence of these alternative approaches may not affect future fertility and endocrine issues of these young patients. 
Staining for vimentin ${ }^{22}$ and cytokeratin ${ }^{23}$ is generally positive in ovarian small-cell carcinoma of the hypercalcemic type. ${ }^{8}$ However, these are not specific markers for this tumor. ${ }^{23-25}$ Parathyroid hormone-related protein is frequently focally positive. ${ }^{3,26}$ In addition, EMA and NSE may be present. ${ }^{8,27,28}$ Although other ovarian tumors may carry these 2 markers, ${ }^{28-30}$ EMA has been asserted to be rarely found in sex-cord tumors that can form an important part of the differential diagnosis. ${ }^{8,31-35}$ However, it has been reported that juvenile granulosa cell tumors could stain positively with EMA. ${ }^{36}$ The focal presence of inhibin ${ }^{37}$ in our patient complicated pathological assessment given that granulosa cell tumors usually stain with this marker. ${ }^{38}$ Since the time of the diagnosis, there has been further study of these lesions, which has shown positivity with CD 10 and WT1 (usually nuclear but in some cases cytoplasmatic staining). Both of these markers were positive in our tumor. ${ }^{31,35}$ In our case, the extremely high mitotic rate and clinical presentation (stage 3 with lymph node metastases at presentation) argue against this diagnosis, and the further immunohistochemical profile is supportive for a diagnosis of smallcell carcinoma of hypercalcemic type. ${ }^{39}$ Negative staining with a range of other immunohistochemical markers, coupled with the morphology, excluded other important tumors such as germ cell tumor (AFP, PLAP, CD30, hCG) and lymphoma (CD45, CD30, ALK1) in our patient. ${ }^{8,21,31}$ The immunohistochemical characterization of ovarian small-cell carcinoma of the hypercalcemic type is summarized in Table 1.

With flow and image cytometry, however, the neoplastic cells may show a diploid DNA content. Accumulation of the $\mathrm{p} 53$ protein has been shown by genetic analysis in 12 of 15 of these tumors, supporting an important role for p53 gene abnormalities in the genesis of this highly aggressive ovarian carcinoma. ${ }^{7}$ Positive staining for p53 of ovarian small-cell carcinoma of the hypercalcemic type has been reported previously. ${ }^{31}$ Alternatively, gain of $12 p$ sequences has been described in (ovarian) germ cell tumors. ${ }^{13}$ The lack of over expression of $12 p$ in our case and positive staining for p53 supported the diagnosis of ovarian small-cell carcinoma of the hypercalcemic type.

\section{Prognostic Factors}

Small-cell carcinoma of the hypercalcemic type is a very aggressive tumor with a grim prognosis. Only patients with a stage IA disease have a reasonable chance of long-term survival. Tumor stage is considered to be the most powerful prognostic factor.

Thirty-three percent of the patients with a stage IA tumor had a long-term recurrence-free survival in contrast to only $10 \%$ of patients with stage IC disease and $6.5 \%$ of those in advanced stages. $^{3}$ In stage IA disease, the prognosis was better when patients were older than 30 years, had a normal serum calcium, the tumor was smaller than $10 \mathrm{~cm}$, and when it had no or few large cells. In addition, a tendency toward a better outcome was observed in patients who were treated by a bilateral salpingooophorectomy, a total abdominal hysterectomy, chemotherapy, and adjuvant radiotherapy compared with those missing 1 or more of these modalities. . $^{3,40}$

The number of mitotic figures has no influence on survival and is similar in the various stages of disease.

\section{THERAPEUTIC OPTIONS}

\section{Surgery}

Although early stage ovarian small-cell carcinoma of the hypercalcemic type is unilateral in $99 \%$ of patients, ${ }^{3}$ various reports support radical surgery with extirpation of the uterus and both ovaries. ${ }^{9}$ Although there is a trend toward better outcome, the number of patients is very low and therefore the efficacy of this approach in premenopausal women is controversial.

It may be deemed desirable to preserve fertility in these young patients. Hence, conservative surgical treatment with sparing the contralateral ovary and uterus might be considered in early stage disease. ${ }^{41,42}$ However, in spite of the poor prognosis for patients with advanced stage small-cell carcinoma of the hypercalcemic type, an aggressive approach with radical resection followed by chemotherapy is widely applied. ${ }^{9,34}$ Conservative debulking

TABLE 2. Reported strategies of treatment in ovarian small-cell carcinoma of the hypercalcemic type

\section{Strategies Used for Ovarian Small-Cell Carcinoma of the Hypercalcemic Type}

Combinations of Agents and Chronology Reference

Recommended treatment strategy:

-surgery, followed by cisplatin and etoposide or BEP and radiotherapy

-neoadjuvant BEP, followed by conservative surgery and radiotherapy

Harrison et $\mathrm{al}^{40}$

iternative treatment strategies

including radiotherapy:

-surgery, followed by cisplatin and vinblastine

-surgery, followed by cisplatin, etoposide, adriamycin, and vincristine

-surgery followed by VPCBAE or neoadjuvant VPCBAE followed by surgery

Alternative treatment strategies

without radiotherapy:

Double agent chemotherapy

-surgery followed by etoposide and adriamycin

-surgery followed by paclitaxel and carboplatin

This report

riple agent chemotherapy

-surgery followed by BEP

-surgery followed by PAC

Young et $\mathrm{al}^{3}$

Young et $\mathrm{al}^{3}$

Senekjian et $\mathrm{al}^{45}$

Sequential chemotherapy

-surgery followed by vincristine, etoposide and cyclophosphamide and subsequently alternating cisplatin and doxorubicin

Induction chemotherapy

-induction with VAC followed by surgery and consolidation with VPB -induction with BEP followed by surgery and consolidation with VAC

Hamilton et $\mathrm{al}^{46}$

Wynn et $\mathrm{al}^{47}$

Reed et $\mathrm{al}^{34}$

Pruett et $\mathrm{al}^{10}$

Florell et $\mathrm{al}^{48}$

The recommended strategy consists of a combination of surgery, radiotherapy and cisplatin/etoposide-based chemotherapy. Surgery is generally characterized by total hysterectomy and bilateral salpingo-oophorectomy. Strategy of neoadjuvant BEP followed by conservative surgery is proposed by this report. The summarized alternative treatment strategies are either more toxic or inferior in comparison to the recommended strategy.

Vinblastine, cisplatin, cyclophosphamide, bleomycin, adriamycin, and etoposide (VPCBAE), cisplatin, adriamycin, and cyclophosphamide (PAC), vinblastine, cisplatin, and bleomycin (VPB). 
surgery followed by chemotherapy and local radiotherapy, however, can be a reasonable alternative approach as illustrated by this case report. Because of the grim prognosis of this disease, regardless of any therapeutic approach, an alternative approach of conservative surgery followed by chemotherapy is proposed (Fig. 2).

\section{Chemotherapy}

Patients with ovarian small-cell carcinoma of the hypercalcemic type receiving adjuvant chemotherapy after surgical intervention may have a better chance on survival, even in FIGO stage IA, compared with those not treated with adjuvant combination chemotherapy. ${ }^{43,44}$

A large variety of chemotherapy regimens, all with limited success, have been applied in the treatment of advanced and recurrent disease (Table 2). Chemotherapy regimes based on the treatment of epithelial carcinoma, CP, CAP, and CHAP (cyclophosphamide, cisplatinum with or without doxorubicine and hexamethylmelamine), had no or only little efficacy, and only responses of short duration were observed. ${ }^{6,10,12,44,49,50}$ The same limited effect has been observed with paclitaxel platinum therapy in advanced stage disease, ${ }^{47} 2$ patients progressed during chemotherapy and 2 patients shortly after the last chemotherapy cycle. ${ }^{40}$ The most favorable results were achieved with BVP and BEP (cisplatinum, bleomycin with vinblastin, or etoposide) regimen used in germ cell tumors. ${ }^{40}$

Poor survival rates may justify a tendency toward more complex approaches consisting of 5 or more different chemotherapeutic agents. Long-term survivors in stage III disease were observed in patients treated with a multiagent chemotherapy consisting of regimen alternating cycles with vinblastine, cisplatin, bleomycin (PVB) and cyclophosphamide, doxorubicin, and etoposide with and without ifosfamide. ${ }^{3,11}$ Another limited number long-term survivors in stage III disease were treated with a regimen consisting of postoperative induction therapy with BEP followed by consolidation courses of vincristine, actinomycin-D, and cyclophosphamide $(\mathrm{VAC})^{51}$ or a regimen consisting of 5 to 6 chemotherapeutic agents (combinations of vinblastine, cisplatin, cyclophosphamide, bleomycin, adriamycin, doxorubucin, and etoposide). ${ }^{45,48}$ However, efficacy and efficiency of these regimens in comparison with the BEP regimen remains to be established.

\section{Radiotherapy}

In the literature, most of the patients with a long-term survival had received radiotherapy after or concurrent with chemotherapy. ${ }^{2,3,40}$ Radiotherapy was administered as whole abdominal or pelvic and paraaortic radiotherapy. In the study of Harrison et $\mathrm{al}^{40} 5$ of the 7 patients who received radiotherapy after or concurrent with chemotherapy are long-term survivors. Three of the 4 patients with stage I disease who did not receive radiotherapy had recurrent disease. In addition, the Young et $\mathrm{al}^{3}$ study showed that 4 of the 5 patients receiving radiotherapy were longterm survivors. Our patient with FIGO stage IIIC disease with enlarged paraaortic lymph nodes was treated local radiotherapy to the paraaortic region. Because of the obvious low number of patients, the possible additional benefits of radiotherapy, in terms of survival, remain to be established.

\section{CONCLUSIONS}

Ovarian small-cell carcinoma of the hypercalcemic type is a rare diagnosis with a grim prognosis, which predominantly occurs at a young age. The tumor can easily be confused with the highly malignant germ cell tumors of the ovary, or with granulosa cell tumors, and should be distinguished from small-cell carcinoma of the pulmonary type, neuroendocrine carcinoma, and from metastases of the pulmonary small-cell tumor.
Although various option of treatment have been described, the best treatment results in early stage disease have been achieved with a multimodality approach consisting of surgery, combination chemotherapy including cisplatinum and etoposide, and radiotherapy (Table 2). This approach resembles largely to the approach of the presented case in stage III disease, resulting in a good outcome and fertility preservation. The treatment regimen was characterized by conservative surgery, 4 cycles BEP (neoadjuvant) chemotherapy, interval debulking surgery, and local radiotherapy to the paraaortic region.

As suggested, the fertility sparing multimodality approach might be feasible for both advanced and early stage disease in ovarian small-cell carcinoma of the hypercalcemic type. A noninferiority trail, comparing a fertility sparing approach with the widely practiced aggressive approach, may show the efficacy of a fertility sparing approach. However, because of the low incidence of this disease, a global rare tumor registration may be a realistic alternative to determine the most favorable treatment option in advanced stage ovarian small-cell carcinoma of the hypercalcemic type.

\section{ACKNOWLEDGMENT}

The authors thank R. Runsink, M.D., Regional Laboratory Zeeland, Department of Pathology, Middelburg, the Netherlands.

\section{REFERENCES}

1. Walt H, Hornung R, Fink D, et al. Hypercalcemic-type of small cell carcinoma of the ovary: characterization of a new tumor line. Anticancer Res. 2001;21:3253-3259.

2. Dickersin GR, Kline IW, Scully RE. Small cell carcinoma of the ovary with hypercalcemia: a report of eleven cases. Cancer. 1982;49: 188-197.

3. Young RH, Oliva E, Scully RE. Small cell carcinoma of the ovary, hypercalcemic type. A clinicopathological analysis of 150 cases. Am J Surg Pathol. 1994;18:1102-1116.

4. Schleef J, Wagner A, Kleta R, et al. Small-cell carcinoma of the ovary of the hypercalcemic type in an 8-year-old girl. Pediatr Surg Int. 1999; $15: 431-434$

5. Malfetano JH, Degnan E, Florentin R. Para-endocrine hypercalcemia and ovarian small cell carcinoma. N Y State J Med. 1990;90:206-207.

6. Ulbright TM, Roth LM, Stehman FB, et al. Poorly differentiated (small cell) carcinoma of the ovary in young women: evidence supporting a germ cell origin. Hum Pathol. 1987;18:175-184.

7. Seidman JD. Small cell carcinoma of the ovary of the hypercalcemic type: p53 protein accumulation and clinicopathologic features. Gynecol Oncol. 1995;59:283-287.

8. Aguirre P, Thor AD, Scully RE. Ovarian small cell carcinoma. Histogenetic considerations based on immunohistochemical and other findings. Am J Clin Pathol. 1998;92:140-149.

9. Patsner B, Piver MS, Lele SB, et al. Small cell carcinoma of the ovary: a rapidly lethal tumor occurring in the young. Gynecol Oncol. 1985;22:233-239.

10. Pruett KM, Gordon AN, Estrada R, et al. Small-cell carcinoma of the ovary: an aggressive epithelial cancer occurring in young patients. Gynecol Oncol. 1988;29:365-369.

11. Tewari K, Brewer C, Cappuccini F, et al. Advanced small cell carcinoma of the ovary in pregnancy: long-term survival after debulking and multiagent chemotherapy. Gynecol Oncol. 1997;66:531-534.

12. Lamovec J, Bracko M, Cerar O. Familial occurrence of small-cell carcinoma of the ovary. Arch Pathol Lab Med. 1995;119:523-527.

13. Oosterhuis JW, Looijenga LH. Testicular germ-cell tumours in a broader perspective. Nat Rev Cancer. 2005;5:210-222.

14. Gershenson DM. Management of early ovarian cancer: Germ cell and sex cord-stromal tumors. Gynecol Oncol. 1994;55:S62-S72.

15. Dickersin GR, Scully RE. Ovarian small cell tumors: an electron microscopic review. Ultrastruct Pathol. 1998;22:199-226.

16. Eichhorn JH, Bell DA, Young RH, et al. DNA content and proliferative activity in ovarian small cell carcinomas of the 
hypercalcemic type. Implications for diagnosis, prognosis, and histogenesis. Am J Clin Pathol. 1992;98:579-586.

17. Rana S, Warren BK, Yamada SD. Stage IIIC small cell carcinoma of the ovary: survival with conservative surgery and chemotherapy. Obstet Gynecol. 2004;103:1120-1123.

18. McMahon JT, Hart WR. Ultrastructural analysis of small cell carcinomas of the ovary. Am J Clin Pathol. 1988;90:523-529.

19. Longy M, Toulouse C, Mage P, et al. Familial cluster of ovarian small cell carcinoma: a new Mendelian entity? J Med Genet. 1996;33: 333-335.

20. Schwobel MG, Stauffer UG. Surgical treatment of ovarian tumors in childhood. Prog Pediatr Surg. 1991;26:112-123.

21. Lifschitz-Mercer B, David R, Dharan M, et al. Small cell carcinoma of the ovary: an immunohistochemical and ultrastructural study with a review of the literature. Virchows Arch A Pathol Anat Histopathol. 1992;421:263-270.

22. Ramaekers F, Haag D, Jap P, et al. Immunochemical demonstration of keratin and vimentin in cytologic aspirates. Acta Cytol. 1984;28:385-392.

23. Davis BW, Morassi LL, Locher GW, et al. Cellular localization of keratin in proliferative epithelial processes and neoplasms of the human ovary. J Cancer Res Clin Oncol. 1983;106:222-228.

24. Dabbs DJ, Geisinger KR. Common epithelial ovarian tumors. Immunohistochemical intermediate filament profiles. Common epithelial ovarian tumors. Immunohistochemical intermediate filament profiles. Cancer. 1988;62:368-374.

25. Denk H, Moll R, Weybora W, et al. Intermediate filaments and desmosomal plaque proteins in testicular seminomas and non-seminomatous germ cell tumors as revealed by immunohistochemistry. Virchows Arch A Pathol Anat Histopathol. 1987;410:295-307.

26. Matias-Guiu X, Prat J, Young RH, et al. Human parathyroid hormone-related protein in ovarian small cell carcinoma. An immunohistochemical study. Cancer. 1994;73:1878-1881.

27. Pinkus GS, Kurtin PJ. Epithelial membrane antigen - a diagnostic discriminant in surgical pathology: immunohistochemical profile in epithelial, mesenchymal, and hematopoietic neoplasms using paraffin sections and monoclonal antibodies. Hum Pathol. 1985;16:929-940.

28. Abeler V, Kjorstad KE, Nesland JM. Small cell carcinoma of the ovary. A report of six cases. Int J Gynecol Pathol. 1988;7:315-329.

29. Niehans GA, Manivel JC, Copland GT, et al. Immunohistochemistry of germ cell and trophoblastic neoplasms. Cancer. 1988;62:1113-1123.

30. Duggan MA, Robertson DI. The cytokeratin profiles of ovarian common "epithelial” tumors. Eur J Gynecol Oncol. 1989;10:73-79.

31. McCluggage WG, Oliva E, Connolly LE, et al. An immunohistochemical analysis of ovarian small cell carcinoma of hypercalcemic type. Int J Gynecol Pathol. 2004;23:330-336.

32. Forster C, Ostertag H, Schmitt J, et al. A case report with immunohistochemical, ultrastructural and cytophotometric analysis and review of the literature. Gen Diagn Pathol. 1997;142:365-370.

33. Buono JP, Dechelotte P, Glowaczower E, et al. Ploidy analysis in a case of ovarian small cell carcinoma with hypercalcemia. Ann Pathol. 1995;15:134-137.

34. Reed WC. Small cell carcinoma of the ovary with hypercalcemia: report of a case of survival without recurrence 5 years after surgery and chemotherapy. Gynecol Oncol. 1995;56:452-455.

35. Bruening W, Gros P, Sato T, et al. Analysis of the $11 \mathrm{p} 13$ Wilms' tumor suppressor gene (WT1) in ovarian tumors. Cancer Invest. 1993;11:393-9.

36. Riopel MA, Perlman EJ, Seidman JD, et al. Inhibin and epithelial membrane antigen immunohistochemistry assist in the diagnosis of sex cord-stromal tumors and provide clues to the histogenesis of hypercalcemic small cell carcinomas. Int J Gynecol Pathol. 1998;17: 46-53.

37. Pelkey TJ, Frierson HF Jr, Mills SE, et al. The diagnostic utility of inhibin staining in ovarian neoplasms. Int J Gynecol Pathol. 1998;17: $97-105$.

38. Flemming P, Grothe W, Maschek H, et al. The site of inhibin production in ovarian neoplasms. Histopathology. 1996;29:465-468.

39. Scott M, McCluggage WG. Current concepts in epithelial tumorigenesis: correlation between morphological and molecular data. Histol Histopathol. 2006;21:81-92.

40. Harrison ML, Hoskins P, du Bois A, et al. Small cell of the ovary, hypercalcemic type - analysis of combined experience and recommendation for management. A GCIG study. Gynecol Oncol. 2006;100:233-238.

41. McHale MT, DiSaia PJ. Fertility-sparing treatment of patients with ovarian cancer. Compr Ther. 1999;25:144-150.

42. Marchetti M, Padovan P, Fracas M. Malignant ovarian tumors: conservative surgery and quality of life in young patients. Eur J Gynecol Oncol. 1998;19:297-301.

43. Young RH, Oliva E, Scully RE. Small cell carcinoma of the hypercalcemic type in the ovary. Gynecol Oncol. 1995;57:7-8.

44. Benrubi GI, Pitel P, Lammert N. Small cell carcinoma of the ovary with hypercalcemia responsive to sequencing chemotherapy. South Med J. 1993;86:247-248.

45. Senekjian EK, Weiser PA, Talerman A, et al. Vinblastine, cisplatin, cyclophosphamide, bleomycin, doxorubicin, and etoposide in the treatment of small cell carcinoma of the ovary. Cancer. 1989;64: $1183-1187$

46. Hamilton S, Beattie GJ, Williams ARW. Small cell carcinoma of the ovary: a report of three cases and a review of the literature. J Obstet Gynecol. 2004;24:169-172.

47. Wynn D, Everett GD, Boothby RA. Small cell carcinoma of the ovary with hypercalcemia causes severe pancreatitis and altered mental status. Gynecol Oncol. 2004;95:716-718.

48. Florell SR, Bruggers CS, Matlak M, et al. Ovarian small cell carcinoma of the hypercalcemic type in a 14 month old: the youngest reported case. Med Pediatr Oncol. 1999;32:304-307.

49. Fignon A, Fetissof F, Calais G, et al. Small cell carcinoma of the ovary. A clinical and anotomo-pathologi entity. J Gynecol Obstet Biol Reprod. 1993;22:372-378.

50. Taraszewski R, Rosman PM, Knight CA, et al. Small cell carcinoma of the ovary. Gynecol Oncol. 1991;41:149-51.

51. Powell JL, McAfee RD, McCoy RC, et al. Uterine and ovarian conservation in advanced small cell carcinoma of the ovary. Obstet Gynecol. 1998;91:846-848. 